\title{
Agência, conhecimento e capacidades críticas no capitalismo contemporâneo: uma abordagem cosmopolita a partir de baixo ${ }^{1}$
}

Vando Borghi

Resumo: Este artigo tem como objetivo focar-se no processo de transformação do conhecimento - algo intrinsicamente heterogêneo, indo de suas diferentes formas de vida e experiências especificamente situadas para uma natureza mais abstrata e universal -, naquilo que Armatya Sen (1991) define como "as bases informacionais de julgamento e justiça", isto é, as bases informacionais sobre as quais as ações e as políticas estão fundamentadas. Trata-se de um processo crucial, visto que contribui decisivamente para estruturar o território no qual as políticas intervirão, estabelecendo como as fronteiras desse território devem ser delimitadas, o que neste deve ser incluído e o que pode ser deixado de lado em uma área legítima de indiferença social, política e burocrática. Tal processo precisa ser histórico e sociologicamente situado, a fim de se compreender plenamente o modo como as capacidades dos atores nele estão implicadas. $\mathrm{O}$ artigo procura apontar para a chamada "armadilha do trajetorismo (trajectorism)", que caracteriza o campo de tensão configurado pelo modo capitalista de traduzir o espaço de possibilidades aberto pela modernidade: a relação conhecimento/ bases informacionais é fortemente afetada pelas iniquidades sociais e concorre

1 Tradução do inglês por Attila Magno e Silva Barbosa. Professor Adjunto IV do Departamento de Sociologia e Política e do Programa de Pós-Graduação em Sociologia da Universidade Federal de Pelotas - barbosaattila@hotmail.com

2 Departamento de Sociologia e de Direito Econômico da Universidade de Bolonha - Itália vando.borghi@unibo.it 
ela mesma para reproduzi-las. Uma abordagem inspirada em um cosmopolitismo de baixo será explorada, considerando as capacidades dos cidadãos - nos termos da capacidade de aspirar - que podem estar ativamente envolvidas no processo de transformação do conhecimento em bases informacionais. Uma redefinição do processo de produção do conhecimento em termos de direito humano à pesquisa parece ser a direção a ser conduzida a fim de estimular essa relação entre capacidade e conhecimento; e as ciências sociais podem encontrar um desafio promissor de revitalização ao conduzirem a si mesmas nessa direção.

Palavras-chaves: agência; conhecimento; capacidades críticas; cosmopolitismo de baixo.

\section{AGENCY, KNOWLEDGE AND CRITICAL CAPACITIES IN CONTEMPO- RARY CAPITALISM: A COSMOPOLITAN FROM BELOW APPROACH}

Abstract: This paper aims at focusing on the process of transformation of knowledge - something intrinsically heterogeneous, going from its being specifically situated in different forms of life and experiences to a more abstract and universal natureinto what Amartya Sen defines as "informational basis for judgment and justice", that is, the informational basis which policies and public action are based on. It is a crucial process, as it strongly contributes to framing the territory over which policies are going to intervene, establishing how the borders of this territory have to be drawn, what has to be included and what can be dropped off into the area of legitimate social, political and bureaucratic indifference. Such a process has to be historically and sociologically situated, in order to fully understand the way actors' capacities are implied in it. The paper points out the so-called "trap of rajectorism" characterizing the field of tension configured by the capitalist mode of translating the space of possibility opened up by modernity: the relationship knowledge/informational basis results strongly affected by social inequalities and concurs itself in reproducing them. An approach inspired from a cosmopolitanism from below is then explored, according to which citizens' capacities - in terms of capacity to aspire - can be actively involved in the process of transformation of knowledge into informational basis. A redefinition of the knowledge-production process in terms of a human right to research seems to be the direction to be addressed in order to empower this relationship between capacity and knowledge; and social sciences can find a promising challenge of revitalization in addressing themselves in this direction.

Key-words: agency; knowledge; critical capacities; cosmopolitism from below. 


\section{Introduç̃̃o}

Este artigo tem como objetivo lançar luz sobre o processo de transformação do conhecimento - algo intrinsicamente heterogêneo, indo de suas diferentes formas de vida e experiências especificamente situadas até chegar a sua natureza mais abstrata e universal -, aquilo que Armatya Sen define como "as bases informacionais de julgamento e justiça”, isto é, as bases informacionais sobre as quais as ações e as políticas estão fundamentadas. ${ }^{3}$ Trata-se de um processo crucial, visto que contribui decisivamente para estruturar o território no qual as políticas intervirão, estabelecendo como as fronteiras desse território devem ser delimitadas, o que neste deve ser incluído e o que pode ser deixado de lado em uma área legítima de indiferença social, política e burocrática. Tal processo precisa ser histórico e sociologicamente situado, a fim de se compreender plenamente o modo como as capacidades dos atores nele estão implicadas. $\mathrm{O}$ artigo procura apontar para a chamada armadilha do trajetorismo, ${ }^{4}$ que caracteriza o campo de tensão configurado pelo modo capitalista de traduzir o espaço de possibilidades aberto pela modernidade: a relação conhecimento/ bases informacionais é fortemente afetada pelas iniquidades sociais e concorre ela mesma para reproduzi-las. Uma abordagem inspirada em um cosmopolitismo a partir de baixo será explorada, considerando as capacidades dos cidadãos - nos termos da capacidade de aspirar -, que podem estar ativamente envolvidas no processo de transformação do conhecimento em bases informacionais. Uma redefinição do processo de produção do conhecimento em termos de direito humano à pesquisa parece ser a direção a ser conduzida a fim de estimular essa relação entre capacidade e conhecimento; e as ciências sociais podem encontrar um desafio promissor de revitalização ao conduzirem a si mesmas nessa direção.

\section{Conhecimento e modernidade: a armadilha do trajetorismo}

Qualquer investigação desses grandes problemas - como a relação entre conhecimento e capacidade humana - precisa, é claro, ser contextualizada no tempo e no espaço. O contexto no qual a relação conhecimento/ capacidade

3 Alguns dos argumentos deste artigo foram apresentados ainda em fase de desenvolvimento em uma comunicação na $16^{\mathrm{a}}$ Conferência Anual do Consórcio Internacional de Teoria Social, realizada no período de 24 a 26 de maio de 2017, em Innsbruck, Áustria.

4 De acordo com antropólogo indiano Arjun Appadurai (2013), o trajetorismo remete às perspectivas teóricas que dão ênfase à idéia de desenvolvimento progessivo, caracterizando-se por ser uma forma de pensar particularmente ocidental, tanto em sua origem quanto no seu impulso. A teoria da modernização seria um exemplo disso. 
deve ser concebido é a longa história da modernidade e das formas como o espaço de possibilidades (relativas ao individualismo, liberdade, autonomia, autodeterminação etc.) aberto pela modernidade foi e é "traduzido" pelo capitalismo. Nós estamos aqui nos referindo à perspectiva segundo a qual o processo contínuo de "estabelecimento de relações de mercado onde até então não havia nenhuma" (Streeck, 2012: 6) é sempre um processo de tradução "de diversos mundos da vida e horizontes conceituais sobre o ser humano" (Chakrabarty, 2000: 71) do material dominante e da interpretação imaterial deste horizonte de possibilidade.

A modernidade precisa ser, de fato, assumida como um termo que se refere "a uma situação autocriada por seres humanos comprometidos com as ideias modernas de autonomia e de domínio, na qual, uma certa interpretação dessas ideias prevalece sobre outras" (Wagner, 2001: 24). A modernidade e o capitalismo desenham um campo de tensão (Borghi; Mezzadra, 2013) no qual a nossa vida comum está constitutivamente imersa. Em tal campo, a armadilha do trajetorismo (Appadurai, 2013, Capítulo 11) é sempre uma emboscada. O trajetorismo está estritamente ligado com a forma ocidental de pensar, ser e fazer. Ele funciona como um profundo "hábito epistemológico e ontológico" segundo o qual o mundo está sempre assumindo uma direção, indo daqui para lá sempre de acordo com uma evolução cumulativa.

O trajetorismo é a ideia de que a seta do tempo tem inevitavelmente um telos, e de que nesse telos podem ser encontrados todos os padrões de mudança, de processos e históricos significativos. A ciência social moderna herda este telos e transforma-o em um método para o estudo da humanidade (Appadurai, 2013: 223).

Essa perspectiva evolucionária assume a forma de uma ideia europeia pós-renascentista de modernidade, "que exige uma expansão global completa para que sua lógica interna seja revelada e justificada" (Appadurai, 2013: 225). O destino dessa trajeória está claramente fixado desde o início, escrito na imagem com a qual a Europa e o mundo ocidental se autorretratam.

Nessa perpectiva, o conhecimento está enraizado em uma visão de expansão progressiva e em uma naturalização de "escalabilidade" (Tsing, 2012), concebido como um saber historicamente dominante e construtor do mundo. De acordo com o modo de escalabilidade de conectar o conhecimento e a transformação do mundo, "a habilidade de expandir-se - e expandir-se, e expandir-se - sem repensar elementos básicos” (Tsing, 2012: 505) é o seu aspecto-chave: 
projetos escaláveis "são aqueles que podem expandir-se sem mudanças" (...) projetos de escalabilidade banem a diversidade significativa, o que significa dizer, a diversidade que pode mudar as coisas" (Tsing, 2012: 507). A possibilidade de conceber a relação entre conhecimento e contrução do mundo a fim de conferir espaço e papel para essa "diversidade significativa" é a questão que está em jogo na investigação deste artigo.

\section{0 conhecimento nas muitas histórias da modernidade e do capitalismo: em busca do cosmopolistismo a partir de baixo}

Próximo e entrelaçado a esse espaço histórico universal e homogêneo, que Dispesh Chakrabarty (2000) identifica como História 1, sempre existem outras histórias ("História 2"), "inerentes ao capital, mas, contudo, interrompidas e pontuadas pelo controle da própria lógica do capital” (Chakrabarty, 2000: 64). Nesse sentido, por exemplo, um trabalhador específico encorpora ambas, História 1 (como diariamente reproduzindo a lógica do capital, atuando como trabalho abstrato) e História 2 (como uma pessoa historicamente, socialmente e culturalmente concreta que pode "adotar outras formas de ser no mundo - além de ser o portador da força de trabalho"). Assim, a ideia de História 2 "nos dá uma base para situarmos nossos pensamentos sobre as múltiplas formas do ser humano e suas relações com a lógica do capitalismo global" (Chakrabarty, 2000: 67).

Essa abordagem do processo histórico ${ }^{5}$ nos capacita para o reconhecimento da pluralidade constitutiva da modernidade, para conceber esta última como um campo que é, já em suas origens, o terreno de uma luta sobre o significado do se moderno e "para compreender a modernidade nem tanto como um "projeto inacabado", mas sim (...) como um campo contestado" (Mezzadra, 2010: 3). Além disso, esta perspectiva salienta um espaço de possibilidades (Santos, 2007) que muda por meio do tempo, mas que está sempre presente em todo lugar. Nesse sentido:

História 1 e História 2, consideradas juntas, destroem a usual distinção topológica do dentro e do fora que marca o debate se se pode dizer devidamente que o mundo inteiro está submetido ao controle do capital. Também não é algo subsumido ao capital. Vivendo em relações íntimas e plurais com o capital, estendendo-se da oposição à neutralidade (Chakrabarty, 2000: 65-6).

5 Não se limita apenas aos estudos históricos e sociológicos (de estudos pós-coloniais): algumas narrativas nos dão uma ideia vívida das tensões e violências concretas ligadas à relação estrutural entre História $1 \mathrm{e}$ 2; veja, por exemplo, Amitav Ghosh, Sea of Poppies (2008). Os contatos entre o trabalho de Chakrabarty e Ghosh são diretamente testemunhados por sua correspondência: Ghosh, Chakrabarty, 2002. 
Por um lado, essa interpretação do processo histórico leva à necessidade de um esforço reflexivo para a descolonização das ferramentas analíticas mediante as quais definimos e pesquisamos nossa própria experiência e o significado do mundo social (Connell, 2007; Rodriguez et al., 2010). Por outro lado, também permite uma outra estratégia intelectual, que vai em uma direção diferente. Enquanto a primeira enfatiza recursos críticos advindos de fora da experiência ocidental para escapar da armadilha do trajetorismo, a segunda estratégia visa a salientar potencialidades críticas que, mesmo se esquecidas ou marginalizadas pela tradução capitalista da modernidade, são (têm sido) internas à própria experiência ocidental. Recordando as palavras de Boaventura de Souza Santos (2009: 106): "muitos dos problemas enfrentados no mundo atual resultam não apenas do desperdício que o ocidente impõe à força sobre o mundo, mas também do desperdício que impõe a si mesmo para sustentar a própria imposição sobre os outros". Assim, de acordo com essa perspectiva, o caminho epistemológico alternativo para a relação entre conhecimento e construção do mundo não é algo já existente e estruturado em algum lugar fora do mundo, possivelmente distante do centro e do ponto de vista do Norte, tal como em uma teoria imaginária unificada do Sul global. Como diz Connell (2006: 262), no que se refere ao campo específico da sociologia do conhecimento:

Um dos problemas da teoria do norte é a sua ideia característica de que uma teoria deve ser uma declaração monológica de uma única verdade em uma única voz. Me parece que uma sociologia genuinamente global deve, no nível teórico, assim como, na pesquisa empírica e na aplicação prática, ser mais uma conversação entre muitas vozes.

Para além de qualquer campo disciplinar específico, a direção que estamos convidando a olhar é aquela do cosmopolitismo, na qual, essa "conversação entre muitas vozes", objetivando evitar a armadilha do trajetorismo e a epistemologia imperialista da escalabilidade, poderia ser plenamente desenvolvida. Contudo, como já foi ressaltado, qualquer relação entre o conhecimento e a construção do mundo tem de ser situada no campo sócio-histórico da tensão produzida pela contínua tradução da modernidade à forma capitalista de vida. Nessa situação, o conhecimento e a construção do conhecimento não são simétricos e universalmente acessíveis. Por um lado, existem desigualdades de acesso ao conhecimento já existentes e codificados; por outro lado, existem imensas diferenças relativas ao processo de transformação das diferentes formas de conhecimento, principalmente as resultantes das experiências que os atores mais 
pobres e desfavorecidos também fazem de seus próprios problemas, em bases informativas. Mais em geral, nossas autoproclamadas "sociedades do conhecimento" (Innerarity, 2013) estão vivenciando problemas relevantes e articulando democraticamente a relação entre conhecimento e política. Nós exploraremos melhor este ponto na seção seguinte, mas já podemos adiantar que esta dramática desigualdade, relativa à transformação do conhecimento (o que e de quem?) em informação pertinente e relevante para o processo de elaboração de políticas, força uma qualificação mais precisa do cosmopolitismo que estamos buscando. O cosmopolitismo, nessa condição de desigualdade, necessita daquilo que Arjun Appadurai (2013: 212) define como o cosmopolitismo a partir de baixo: uma forma de "democracia profunda" que visa transformar os "ideais constitutivos burgueses das formas diárias de consciência e comportamento, na qual o debate pode ser respeitosamente conduzido e as vozes dos mais fracos, dos mais pobres, e em particular as mulheres, recebem total consideração" e na qual estas vozes possam plenamente fazer parte da produção do quadro de conhecimento e de informação dos mecanismos de elaboração de políticas.

\section{As bases informacionais como terreno para o cosmopolitismo a partir de baixo}

Ao seguir a direção que estamos esboçando aqui, identificamos na dimensão cognitiva - isto é, na transformação do conhecimento em informação útil - do processo de elaboração de políticas um terreno crucial para trabalhar o cosmopolitismo a partir de baixo. A relação entre a dimensão cognitiva e as políticas sociais nos seus sentidos amplos é de fato sistemática e penetrante. Ao mesmo tempo, é uma relação crucial, à medida em que engloba (intencionalmente ou não) avaliações fundamentais relativas à justiça social que têm efeitos nas mais diferentes esferas da experiência social e individual. As políticas e ações públicas e os programas sociais, em outras palavras, tudo o que remete ao domínio público e ao debate público, estão fundamentadas em bases cognitivas que permanecem implícitas e obscuras. A natureza política destas bases cognitivas é a naturalização do seu enquadramento e de sua apresentação como questões meramente técnicas. As decisões e ações (políticas, ações públicas, programas, planos socioeconômicos etc.) são legitimadas em um contexto de conhecimento comum - que é um produto sócio-histórico - no qual bases cognitivas específicas inquestionáveis são assumidas: quantitativas, padronizadas, abstratas, avaliações de desempenho, em forma de estatísticas, índices, avaliações comparativas e outros dispositivos de governança formalizados e quantificados, fortemente hegemônicos. Mas, é aqui que reside a necessidade de um programa 
de pesquisa, as convenções - ou seja, estruturas de significado por meio das quais uma situação ou condição pode ser definida, classificada, categorizada e também calculada - sobre as quais (também) este quantitativo de dispositivos permanece fundamentado fora do domínio público.

As questões aqui introduzidas já têm sido discutidas com autoridade. Como Armatya Sen as definiu, ações e decisões coletivamente relevantes sempre incorporam e usam bases informacionais de julgamento para justiça (BIJJ):

Um conceito fundamental nesta análise é o de "fundação informacional" de um sistema avaliativo. Em cada estrutura avaliativa, alguns tipos de problemas factuais são tomados como importantes por si mesmos, outros não tanto. As primeiras variáveis, aquelas que refletem os fins básicos de um sistema avaliativo constituem as bases informacionais de julgamentos avaliativos neste sistema (Sen, 1991:16).

Nesse sentido, as BIJJ estão no cerne de um processo de avaliação, sendo utilizadas em questões relativas à política social, política laboral, entre outras. O que deve ser levado em conta como informação quando as políticas sociais específicas são concebidas e executadas são fatores, como: a medida de política laboral prevista, como a força de trabalho que tem de ser mobilizada e como o trabalho desta deve ser organizado, como a qualidade e a segurança em um ambiente de trabalho são avaliadas, como uma praça pública ou uma rua tem de ser estruturadas etc. E o que não deve ser levado em conta, isto é, aquilo que o modo dominante de conceber e de executar políticas considera informação marginal ou irrelevante, podem ser: quais os tipos de lacunas e de desconhecimento são política e burocraticamente transformados em áreas legitimadas de indiferença? Recorrendo novamente às palavras de Armatya Sen (1999: 56-57):

Cada abordagem avaliativa pode, em grande medida, ser caracterizada por sua base informativa: a informação necessária para fazer julgamentos usando essa abordagem e - não menos importante - a informação que é "excluída" de um papel em uma avaliação direta. As exclusões informativas são componentes importantes de uma abordagem avaliativa, pois não se permite a informação excluída ter influência direta sobre os julgamentos avaliativos e à medida que isso é feito normalmente de forma implícita, o caráter da abordagem pode ser fortemente influenciado pela insensibilidade à informação excluída (...). De fato, a verdadeira "sacada" de uma teoria da justiça pode, em grande medida, ser entendida a partir de sua base informativa: o que é informação - ou não é - passa a ser diretamente relevante. 
Uma abordagem cosmopolita a partir de baixo desses problemas poderia focar-se tanto nos processos gerais referentes a como um conhecimento é transformado em informação e outro não, quanto nas várias formas dos resultados desta transformação, tratando-os como objeto e incorporando-os em uma crescente pluralidade de dispositivos técnico-burocráticos (códigos, índices, padrões e assim por diante) que afetam a nossa vida social diária. Nossa vida diária comum está cada vez mais condicionada pelas experiências diversificadas da "governança pelos números" (Supiot, 2015); e pela crescente burocratização neoliberal de nossas atividades de trabalho diárias (Hibou, 2012). Nesse sentido, a dimensão cognitiva é mais ou menos absorvida em um processo de privatização, sendo muitos os dispositivos nos quais ela é incorporada (padrões, códigos e procedimentos técnicos), produzida e disseminada pelas agências e organizações privadas (Singer, 1996; Brunsson; Jacobsson, 2000; Ong; Collier, 2005; Lampland; Leigh Star, 2009). Em geral, nós podemos absorver uma transformação intensa de conhecimento em informação formatada (objetificada e técnica), atuando de modo eficiente para um "modo gerencial de dominação" que compõe uma "dominação complexa ou gerencial" que "consiste em uma alteração contínua dos contornos da realidade como se o mundo nele se inscrevesse, como um lugar de constante mudança" (Boltanski, 2011: 123 e 127).

\section{0 direito humano à pesquisa e ao conhecimento (sociológico)}

A relação entre a perspectiva que aborda as bases informacionais e o papel do conhecimento (produção e acesso) para as vozes e experiências mais excluídas, marginais e subalternas é bastante direta e deve estar imediatamente no centro de qualquer abordagem inspirada em um cosmopolitismo a partir de baixo. Como o foco de Armatya Sen são as bases informacionais, em uma perspectiva cosmopolita a partir de baixo, o conceito de capacidade desempenha um papel crucial no esforço de reformulação para um significado não retórico de "sociedades do conhecimento". Em relação a este último aspecto, o que está em jogo aqui é a relação entre cultura - enquanto uma capacidade específica, a "capacidade de aspirar", de acordo com a qual a cultura tem uma natureza pragmática e uma orientação para o futuro, para um horizonte mais ou menos aberto de possibilidades - e voz, definida como "a capacidade de debater, contestar, indagar e participar criticamente" (Appadurai, 2013: 189). O desenvolvimento da capacidade cultural das pessoas, em termos de capacitação da "capacidade de aspirar", significa reformular o alcance das possibilidades 
de ações dos indivíduos (em particular, os mais pobres e os excluídos), escapando do destino que as condições sociais parecem condená-los e não aceitando como "naturais" determinadas ordens morais ou políticas. $\mathrm{O}$ valor da pesquisa de Appadurai sobre a "capacidade de aspirar", no que diz respeito à nossa perspectiva sobre as BIJJ, consiste em mostrar como as capacidades de aspirar e de voz se entrelaçam e reforçam-se mutuamente (Bifulco, 2013: 183). Este reforço produz uma transformação qualitativa concreta do conhecimento e da base informacional relativos às questões sobre as quais as capacidades de aspirar e de voz são exercidas. Abre caminho para uma "política de interpretação das necessidades" (Fraser, 1989), permitindo que os cidadãos pobres, marginais e excluídos elaborem suas próprias estratégias para definir e representar realidades problemáticas, vínculos e possibilidades e entrem ativamente na esfera pública, mudando os termos de reconhecimento e, dessa forma, reformulando as próprias BIJJ. De acordo com esta perspectiva e no contexto das autoproclamadas "sociedades do conhecimento", a relação entre pesquisa, conhecimento dos cidadãos e as formas como o conhecimento é processado (ou não) a fim de tornar-se base informativa das políticas deve ser fortemente repensada. Uma reflexão inspirada em um cosmopolitismo a partir de baixo deve ser tratada em termos de direito humano à pesquisa (Appadurai, 2013). Este direito pertence tanto aos pesquisadores quanto aos seus públicos, como uma responsabilidade pública e coletiva compartilhada. É nesta arena, neste espaço de construção e busca coletiva pelo direito humano à pesquisa que a "sociologia pública" - que acontece por toda parte, é um "processo de educação mútua” entre sociólogos e seus públicos (Burawoy, 2005: 8) - pode ser concretamente buscada e realizada. De um modo mais geral, o papel central das ciências sociais (em uma interpretação pragmática), e da sociologia em particular, considerando que as questões que estamos discutindo aqui sejam particularmente evidentes, é "serem chamadas para produzir a base informacional necessária para o processo permanente de reconstrução da esfera pública" (Zimmerman, 2006: 481).

Reformulada nos termos do cosmopolitismo a partir de baixo, a pesquisa "não é apenas a produção de idéias originais e novos conhecimentos (como é normalmente definido na academia e por outras instituições baseadas no conhecimento)", mas também consiste na "capacidade de aumentar sistematicamente os horizontes do conhecimento atual de alguém em relação a alguma tarefa, objetivo ou aspiração" (Appadurai, 2013: 282). Assim, um direito humano à pesquisa diz respeito ao "direito às ferramentas através das quais qualquer cidadão pode aumentar sistematicamente esse estoque de conhecimento que 
considerem mais vital à sua sobrevivência como seres humanos e às suas reivindicações como cidadãos" (Appadurai, 2013: 270). A relação entre a capacidade de aspirar e o conhecimento dos cidadãos é então bastante evidente, pois sem aspiração "não há pressão para saber mais e sem ferramentas sistemáticas para obter novos conhecimentos relevantes, a aspiração degenera em fantasia ou desespero" (Appadurai, 2013: 283).

\section{Sociologia, crítica e cosmopolitismo a partir de baixo}

O cosmopolitismo a partir de baixo, aqui explorado, ainda representa uma maneira minoritária de combinar o pensamento e a experiência do Norte e do Sul (Rao; Woolcock, 2007). No entanto, é uma perspectiva promissora e fascinante de renovação do enquadramento do "espaço interpretativo" introduzido pela modernidade (Wagner, 2001) e de uma crítica do modo capitalista dominante de traduzir autonomia e domínio, sem substituí-lo com um já estruturado sistema teórico monológico. As experiências de injustiças sociais são muitas e heterogêneas, incluindo não apenas os casos de exploração sociologicamente bem "codificados" ligados às condições de trabalho, mas também as pessoas que não têm acesso ao trabalho assalariado e "àqueles que enfrentam expulsões de terras, privatização da água e, de forma mais ampla, degradação do meio ambiente" (Burawoy, 2008: 384). Qual tipo de conhecimento esses povos elaboram com base em sua própria experiência? Como a pesquisa pode contribuir para a capacidade de aspirar desses indivíduos? De que maneira suas vozes e seus conhecimentos poderiam se transformar em bases cognitivas para os processos de formulação de políticas? Aqui reside um campo de trabalho enorme e desafiador para uma sociologia que não renuncia à sua natureza crítica, considerando-se que, independentemente da relação entre sociologia e crítica, ela "deva ser sobre questões pertinentes e não sobre respostas corretas" (Schuurman, 2009: 841). Recordando novamente a busca de Burawoy pela unificação de diferentes vocabulários de injustiça social, quaisquer tentativas incertas e problemáticas de procurar uma linguagem comum - para unificar as muitas e diversas experiências de injustiças sociais daqueles que enfrentam a última onda de mercantilização - certamente pede uma abordagem sociológica (além de outras ciências sociais). Aqui está o terreno para explorar as possibilidades desse diálogo entre muitas vozes, além de qualquer divisão epistemológica (mais do que geográfica) entre qualquer tipo de Norte e qualquer tipo de Sul, no qual constitui-se uma verdadeira "sociologia mundial" (Connell, 2010). Os sociólogos podem desempenhar um 
papel relevante, colocando sob suas lentes críticas o processo por meio do qual (alguns) conhecimentos se tornam (ou não) base cognitiva e desenvolvem o direito à pesquisa.

Nesse papel, usando os termos de Bauman (como o próprio Burawoy, 2008: 385), os sociólogos devem atuar mais como intérpretes sensíveis do que como legisladores omniscientes, intérpretes sensíveis interessados na co-evolução entre seu próprio vocabulário científico e o conhecimento heterogêneo resultante da experiência dos atores sociais em diferentes questões. Aprofundando a relação entre sociologia e crítica, Luc Boltanski (2011) desenha um mapa seminal de uma possível postura sociológica de observação. O seu mapa apresenta algumas possíveis configurações das formas como a relação entre sociologia e crítica pode ser estruturada, lançando luz também sobre o terreno referente às questões - reestruturação da transformação do conhecimento em base informacional e o papel que um direito humano à pesquisa desempenha a esse respeito - aqui discutidas. Resumidamente, Boltanski (2011: 75-76) identifica duas possibilidades de lidar com a realidade social como pesquisador (crítico). A primeira consiste em descrever "um mundo social já existente". É um modelo que funciona como uma cartografia das estruturas, na qual qualquer indivíduo é lançado, estruturando e condicionando, dessa maneira, o comportamento dos atores em seus ombros para aquilo que Chakrabarty descreve nos termos de uma narrativa histórica (História 1) resultante do desdobramento da lógica abstrata do desenvolvimento capitalista. Uma história já feita, em que lugares e pessoas são "intercambiáveis entre si" (Chakrabarty, 2000: 71). Aqui, as descrições são feitas a partir do topo, "as pessoas humanas, mais ou menos agrupadas e encaradas à medida em que atuam (como atores)" (Boltanski, 2011: 43-4).

Uma segunda configuração resulta em uma descrição na qual a realidade é "um mundo social em processo de realização". Levando em conta seriamente as formas como os indivíduos admitem e realizam a sua realidade, salientando a sua "economia moral" (Thompson, 1974). Uma sociologia pragmática irá iluminar as competências interativas e interpretativas dos indivíduos; bem como a História 2 "nos encaminha para narrativas mais afetivas da pertença humana", nas quais as formas de vida não podem ser incluídas exaustivamente nas categorias abstratas da História 1. As descrições são realizadas 'vindas de baixo' e seu objeto privilegiado são situações, priorizando as competências interativa e interpretativa dos 'atores"' (Boltanski, 2011: 44).

Considerando que a primeira estratégia de descrição corresponde a uma perspectiva sociológica crítica tradicional, a segunda corresponde a uma 
sociologia das capacidades críticas, desenvolvida particularmente pela abordagem pragmática francesa da sociologia (Boltanski; Thévenot, 2006). Além de seus próprios limites e pontos fortes, precisamos combinar o programa da sociologia crítica e o programa de sociologia pragmática. No entanto, uma terceira possibilidade pode ser adicionada a estas duas, com base no que Burawoy (2005: 264) define "sociologia pública orgânica". Esta última representa, é claro, uma abordagem bastante diferente das questões que estamos explorando aqui. De acordo com uma perspectiva de "sociologia pública orgânica":

O sociólogo trabalha em estreita ligação com um visível, denso, ativo, local e, muitas vezes, contra-público. A maior parte da sociologia pública é de fato um tipo orgânico - sociólogos que trabalham com um movimento trabalhista, associações de bairro, comunidades de fé, grupos de direitos dos imigrantes, organizações de direitos humanos. Entre o sociólogo público orgânico e um público está um diálogo, um processo de educação mútua (...). O projeto de tais sociologias públicas é tornar visível o invisível, fazer do particular, público, validar essas conexões orgânicas como parte de nossa vida sociológica (BURAWOY, 2005: 264).

Mais do que a imagem tradicional do "intelectual envolvido", o que podemos lembrar aqui, considerando o problema da relação pesquisador/ campo de pesquisa, é do conceito de "praticante reflexivo" (Schön, 1983).

Inspirados pela característica desse profissional, podemos conceber o(a) sociólogo(a) como um pesquisador(a) envolvido(a) em uma (inter)ação que recusa confinar o seu (ele ou ela) papel a uma solução técnica do problema (ainda que "engajada"), de expertise sociológica, ${ }^{6}$ e que está envolvido em todas as fases que um público atravessa quando enfrenta uma situação problemática, desde a definição do problema até a sua solução. Um envolvimento em que ela/ele tem que combinar sua competência específica, que varia da descrição "a partir de cima" para aquela "a partir de baixo", com um terceiro tipo de esforço (crítico), que é a "reflexão em ação", desenvolvendo e amadurecendo, nas palavras de Burawoy, um "processo de educação mútua" entre o sociólogo e o seu público.

6 Para argumentos contrários à interpretação da relação entre conhecimento/ cidadãos em termos de expertise, ver, por exemplo, Levine (2007). Muito interessante, a esse respeito, é, ao contrário disso, a experiência da associação "Parceiros para Pesquisa e Pesquisa em Conhecimento Urbano". Isso vai exatamente na direção oposta (Appadurai, 2013, em particular o Capítulo 14). 
Quadro 1 - Estratégias de abordagens (críticas) sociológicas da relação conhecimento/ base informacional

\begin{tabular}{lll}
\hline Enquadramento & Definição do mundo social & Prática dos pesquisadores \\
\hline Sociologia crítica & $\begin{array}{l}\text { Narrativa do mundo já } \\
\text { realizada }\end{array}$ & $\begin{array}{l}\text { Uma descrição, do topo, de } \\
\text { estruturas sociais objetivas; } \\
\text { crítica como expertise }\end{array}$ \\
$\begin{array}{l}\text { Sociologia das capacidades } \\
\text { críticas }\end{array}$ & $\begin{array}{l}\text { Narrativa do mundo em } \\
\text { processo de realização }\end{array}$ & $\begin{array}{l}\text { Uma descrição, a partir de } \\
\text { baixo, das competências } \\
\text { (críticas) dos atores; crítica } \\
\text { como parte estrutural da } \\
\text { vida social }\end{array}$ \\
& $\begin{array}{l}\text { Estabelecendo um mundo de } \\
\text { práticas co-evolutivas (estu- } \\
\text { diosos/ públicos) (mundos } \\
\text { possíveis) }\end{array}$ & $\begin{array}{l}\text { Uma educação mútua (es- } \\
\text { tudiosos/ públicos) visando } \\
\text { mundos possíveis }\end{array}$ \\
\hline baixo & & \\
\hline
\end{tabular}

Assim, resumindo possíveis estratégias de abordagem sociológica (crítica) para a relação entre conhecimento e base informacional, não podemos negar que o mundo social tenha uma natureza objetiva, isto é, de certa forma já dada, e que é necessário apontar as suas regras e os seus mecanismos (digamos, uma narrativa de História/ Sociologia 1). No entanto, também podemos trabalhar para apontar as capacidades críticas dos atores sociais (uma narrativa da História/ Sociologia 2) e desenvolver uma "sociologia pública" por meio da qual os estudiosos (comunidades e línguas científicas) e seus públicos (com seus próprios critérios, capacidades, competências, interpretações etc.) mudam mutuamente. O caminho para uma "justiça cognitiva" (Meneses et al., 2007) ainda é longo, mas, viajar por meio dos mapas (hesitantes e incertos) inspirados por uma perspectiva cosmopolita a partir de baixo promete ser excitante e muito animador.

\section{Referências}

APPADURAI, Arjun. The future as cultural fact, London-New York, Verso, 2013, $328 \mathrm{p}$. BIFULCO, Lavinia. Citizen participation, agency and voice. European Journal of Social Theory, November 2012, pp. 174-187.

BOLTANSKI, Luc. On Critique. A Sociology of Emancipation. Cambridge, v. 56, n. 1, February 2013, pp. 86-88.

BOLTANSKI, Luc; THÉVENOT, Laurent. On Justification: Economies of Worth. Princeton, Princeton University Press, 2006, 389 p.

BORGHI, Vando; MEZZADRA, Sandro. In the Multiple Shadows of Modernity. Strategies of Critique of Contemporary Capitalism, Saarbrücken, Lambert Academic Publishing, 2011. 
BRUNSSON, Nils; JACOBSSON, Bengt. A world of standards. Oxford, Oxford University, 2002, $198 \mathrm{p}$.

BURAWOY, Michael. The public turn. From labor process to labor movement. Work and Occupations, California, v. 35, n. 4, November 2008, pp. 371-387.

. American Sociological Association Presidential Address: For a Public Sociology, American Sociological Review, California, v. 70, n. 2, June 2005, pp. 4-28,

CHAKRABARTY, Dipesh. Provincializing Europe, Princeton University Press, Princeton and Oxford, 2000.

CONNELL, Raewyn. Northern theory, the political geography of general social theory, Theory and Society, v. 35, n. 2, April 2006, pp. 237-264.

. How Can We Weave a World Sociology? Global dialogue. Isa Newsletter, Austrália, v. 1, n. 2, November 2010. Disponível em: <http://www.isa-sociology.org/ global-dialogue/>. Acesso em: 18 nov. 2018.

FRASER, Nancy. Talking About Needs: Interpretive Contexts as Political Conflicts in Welfare-State Societies. Ethics, Chicago, v. 99, n. 2, January 19892, pp. 291-313.

GHOSH, Amitav; CHAKRABARTY, Dear. A correspondence on Provincializing Europe. Radical history review, Australia, n. 83, 2002, pp. 146-172.

HIBOU, Beatrice. La bureaucratization du monde. Paris, La Découverte, 2012, 223 p.

INNERARITY, Daniel. The Democracy of Knowledge. New York-London, Bloomsbury, 2013, 224 p.

LAMPLAND, Martha; STAR, Susan Leigh. (eds.) Standards and their Stories. How Quantifying, Classifying and Formalizing Practices Shape Everyday Life, Ithaca, Cornell U.P, 2009.

LEVINE, Peter. Collective Action, Civic Engagement, and the Knowledge Commons. In: C. Hess and E. Ostrom (eds.), Understanding Knowledge as a Commons. From Theory to Practice, Cambridge-London, The MIT Press, 2007.

MENESES, Maria Paula; NUNES, João Arriscado; SANTOS, Boaventura de Sousa. Opening Up the Canon of Knowledge and Recognition of Difference. In: SANTOS, Boaventura. de Sousa (Ed.), Another Knowledge is Possible: Beyond Northern Epistemologies. London, Verso, 2007, pp. vii-lxii.

MEZZADRA, Sandro. How many histories of labor? Towards a theory of postcolonial capitalism, paper presented at the Conference "After Europe: postcolonial knowledge in the age of globalization", University of Chicago, 12 March 2010.

ONG, Aihwa; COLLIER, Stephen J. (eds.) Global assemblages: technology, politics, and ethics as anthropological problems, Oxford, Wiley-Blackwell, 2005, $512 \mathrm{p}$.

RAO, Vijayendra.; WOOLCOCK, Michael. The disciplinary monopoly in development research at the World Bank, Global governance, v. 13, n. 4, October-December 2007, pp. 479-484. 
RODRIGUEZ, Encarnacion Gutierrez; BOATCA, Manuela; COSTA, Sérgio. (eds.), Decolonizing European Sociology, Farnham-Burlington, Ashgate, 2010.

SANTOS, Boaventura de Sousa. A non-Occidentalist West? Learned ignoranceand ecology of knowledge. Theory, culture and society, London, v. 26, n. 7-8, December 2009, pp. 103-125.

SANTOS, Boaventura de Sousa (ed.) Another Knowledge is Possible. Beyond Northern Epistemologies, London, Verso, 2007, 447 p.

SCHÖN, Donald A. The reflexive practitioner. New York, Basic Books, 1983, 384 p.

SCHUURMAN, Frans Johan. Critical development theory: moving out of the twilight zone. Third world quarterly, v. 30, n. 5, junho 2009, pp. 831-848.

SEN, Amartya. Welfare, Preferences and Freedom. Journal of Econometrics, v. 50, n. 1-2, October 1991, pp. 15-29.

. Development as Freedom. Oxford, Oxford University Press, 1999, 366 p.

SINGER, Benjamin. Towards a sociology of standards. Problems of criteria society. In: The Canadian Journal of Sociology, v. 21, pp. 203-221.

STREECK, Wolfgang. How to Study Contemporary Capitalism? Archives Européennes de Sociologie. Cambridge, v. 53, n. 1, Abril 2012, pp. 1-28.

SUPIOT, Alain. La gouvernance par les nombres. Paris, Fayard, 2015, 512 p.

THOMPSON, Edward Palmer. Time, work-discipline and industrial capitalism. In: FLINN, Michael Walter.; SMOUT, T. Christopher (eds.) Essays in social history, Oxford: Clarendon Press, 1974, 289 p.

TSING, Anna Lowenhaupt. On Nonscalability. The Living World Is Not Amenable to Precision-Nested Scales. In: Common Knowledge, Duke University Press, v. 18, n. 3, pp. 505-424, 2012.

WAGNER, Peter. Modernity, capitalism and critique. Thesis eleven, v. 66, n. 1, august 2001, pp. 1-31. London: Sage.

ZIMMERMAN, Bénédicte. Pragmatism and the capability approach. Challenges in social theory and empirical research. European journal of Social Theory, Paris, v. 9, n. 4, November 2006, pp. 467-484.

Recebido em 18/06/2017

Aprovado em 23/02/2018

\section{Como citar este artigo:}

BORGUI, Vando. Agência, conhecimento e capacidades críticas no capitalismo contemporâneo: uma abordagem cosmopolita a partir de baixo. Contemporânea - Revista de Sociologia da UFSCar, v. 8, n. 2, jul.- dez. 2018, pp. 569-584. 